\title{
Study on the Decoupling Evaluation of Economic Development and Energy Consumption in Beijing- Tianjin-Hebei Region*
}

\author{
Dan $\mathrm{Wu}$ \\ School of Economics and Management \\ North China University of Technology \\ Beijing, China 100144
}

\author{
Siqi Cao \\ School of Economics and Management \\ North China University of Technology \\ Beijing, China 100144
}

\author{
Heyan Xu \\ School of Economics and Management \\ North China University of Technology \\ Beijing, China 100144
}

\begin{abstract}
Energy is a strategic resource for national economic and social development. With the rapid advancement of Beijing-Tianjin-Hebei integration, great attention has been paid to the energy consumption of Beijing-Tianjin-Hebei region. Based on the analysis of the economic development and energy consumption of Beijing-Tianjin-Hebei region, this paper uses the elastic analysis method to construct the decoupling state discrimination model for the economic development and energy consumption and utilization of Beijing-Tianjin-Hebei region, and the decoupling situation of energy consumption and utilization of Beijing-Tianjin-Hebei region from 1997 to 2016 is evaluated. It combines the industrial structure with the growth trend of energy consumption utilization of Beijing-Tianjin-Hebei region, the internal mechanism of the decoupling between economic development and energy consumption utilization is comprehensively analyzed. The results show that there is a strong correlation between economic development and energy consumption and utilization in Beijing-Tianjin-Hebei region, and the decoupling between economic development and energy consumption has not yet been achieved.
\end{abstract}

Keywords-Beijing-Tianjin-Hebei region; energy consumption; decoupling evaluation

\section{INTRODUCTION}

Beijing-Tianjin-Hebei region is one of the three major economic growth poles in China as well as one of the important energy consumption centers in China. The rapid growth of the population of Beijing-Tianjin-Hebei region and the rapid development of the economy has triggered high attention to energy consumption. The energy consumption

*Fund Project: National Natural Science Foundation Youth Project (Grant No. 71603004); Beijing Social Science Fund Youth Project (Grant No. 17GLC064); Outstanding Young Talents Cultivation Program of North China University of Technology (Grant No. XN018035); Innovative Engineering Project of North China University of Technology (Grant No. 18XN151). structure affects the pace of industrial transformation and upgrading of Beijing-Tianjin-Hebei region. Therefore, it is necessary to speed up getting rid of the reliance on economic development for energy consumption and realize the "decoupling" between economic development and energy consumption, thus promoting the integration of Beijing, Tianjin and Hebei. The essence of the "decoupling" of economic development and energy consumption is that under the premise of maintaining economic and social growth, the efficiency of energy consumption utilization continues to increase rapidly, while the growth rate of total energy consumption utilization gradually slows down. Finally, the total energy consumption utilization reaches the peak, and zero or even negative growth in energy consumption is achieved.

Decoupling is given different meanings in different subject areas. In the 1990s, foreign decoupling theory was generally applied to the assessment of the use of resources and environment, which mainly studied economic growth and material resource consumption, energy consumption, agricultural production and trade, traffic volume, environmental pollution and other issues [1], [2], [3], [4], [5] Domestic research is in its infancy. With the emergence of resource and environmental issues, the theoretical research and practical discussion of decoupling has been further deepened. At present, many scholars at home and abroad have mainly discussed the definition, state division and methods of decoupling. First of all, from the definition of decoupling, it is mainly used to reflect the change in the degree of dependence between economic growth and material consumption [6]. Secondly, from the perspective of the decoupling state, the OECD countries have established an index system based on the driving force-environmental pressure-environmental state to analyze the decoupling situation between economic development and material consumption and environmental pressure, and divided it into 
the views of Vehmas and Tapio and other scholars, the decoupling is further divided into strong decoupling, weak decoupling, degenerative decoupling, strong negative decoupling, weak negative decoupling, expansionary negative decoupling, growth linkage, and degenerative linkage. [7], [8], [9]. At the same time, from the research methods, the decoupling method has been introduced into the field of resources and environment by the World Bank in recent years [10], and has gradually developed into a decoupling analysis with the characteristics of resources and environment. Decoupling evaluation methods mainly include variation comprehensive analysis method, decoupling index method, elastic analysis method, decoupling analysis method based on complete decomposition technology, IPAT model method, descriptive statistical analysis method, econometric analysis method and differential regression coefficient method [11]. From the practical application of the decoupling theory, scholars have carried out research on the decoupling between economic growth and energy consumption in the Beijing-Tianjin-Hebei region from the aspects of energy carbon emissions and transportation carbon emissions in the Beijing-Tianjin-Hebei region [12], [13], [14], [15], [16], [17]. The energy consumption is affected by the industrial structure. The key to the decoupling of economic development and energy consumption in the Beijing-Tianjin-Hebei region lies in the rationality of the energy consumption structure of the three industries. The current research mainly focuses on the decoupling of economic development and resource environment in the Beijing-Tianjin-Hebei region while there are rare research literature on the decoupling between economic development and energy consumption and its internal mechanism from the energy consumption of the three industries in the BeijingTianjin-Hebei region.

The decoupling of energy consumption in BeijingTianjin-Hebei region is an important part of decoupling theory and practical application. However, Chinese scholars still lack comprehensive and systematic research. In view of this, it is necessary to apply the decoupling theory to the different periods of economic and social development in Beijing-Tianjin-Hebei region, and conduct a comprehensive and systematic study on the decoupling situation of economic development and energy consumption utilization in Beijing-Tianjin-Hebei region. Firstly, referring to the index system of the OECD in the decoupling methodology, the elastic analysis method is used to systematically evaluate the decoupling tense of economic development and energy consumption utilization in Beijing-Tianjin-Hebei region from 1997 to 2016. Then, this paper comprehensively analyzes the internal mechanism of decoupling between economic development and energy consumption of BeijingTianjin-Hebei region; finally, it makes recommendations for accelerating the decoupling of economic development and energy consumption in Beijing-Tianjin-Hebei region.

\section{ANALYSIS OF THE ECONOMIC DEVELOPMENT AND ENERGY CONSUMPTION EVOLUTION OF BEIJING-TIANJIN- HEBEI REGION}

Although Beijing, Tianjin, and Hebei are geographically adjacent, the economic development is not balanced. Overall, in 2017, although Hebei's GDP was higher than that of Beijing and Tianjin, the per capita GDP was far from that of Beijing and Tianjin. The economic development of BeijingTianjin-Hebei region showed an unbalanced growth trend. As the capital of China, Beijing has a unique economic resource. In 2017, Beijing's GDP increased by $9.08 \%$ yearon-year; although Hebei Province is close to Beijing and Tianjin, it has long been affected by the strong agglomeration effect of Beijing and Tianjin, which has caused its resources to be excessively concentrated in Beijing and Tianjin, resulting in serious resource loss in Hebei Province. Hebei's per capita GDP was significantly lower than that of Beijing and Tianjin, but Hebei's GDP grew by as much as $12.14 \%$. From the perspective of the total energy consumption of Beijing-Tianjin-Hebei region in 2017, Hebei Province has the largest total energy consumption value of 297.744 million tons of standard coal, followed by Tianjin, with 82.446 million tons of standard coal; Beijing cost the least, with 69.671 million tons of standard coal. Hebei's total energy consumption accounted for $66.21 \%$ of the total energy consumption of Beijing-Tianjin-Hebei, Beijing accounted for $15.47 \%$, and Tianjin accounted for $18.32 \%$. The total amount of Hebei Province is significantly higher than that of Beijing and Tianjin. In 2017, Beijing's total energy consumption increased by $1.99 \%$ year-on-year; Tianjin's total energy consumption decreased by $0.19 \%$ yearon-year; Hebei's total energy consumption increased by $1.36 \%$.

From the perspective of the economic growth rate of Beijing-Tianjin-Hebei region, Tianjin has the highest economic growth rate in Beijing-Tianjin-Hebei region, followed by Beijing, and Hebei's economic growth rate has experienced a large decline in 2014. Judging from the development trend of economic growth rate in BeijingTianjin-Hebei region, Beijing's economy is relatively stable, Tianjin's economy has experienced a certain degree of decline, while Hebei has shown an upward trend in the past two years. From the comparison of the economic growth rate of secondary industry in Beijing-Tianjin-Hebei region, from 2011 to 2015, the economic growth rate of Beijing-TianjinHebei region has shown a downward trend. Since 2015, the economic growth rate has been rising year by year, and Hebei has the fastest growth rate. The growth rate is relatively flat as shown in "Fig. 1". 


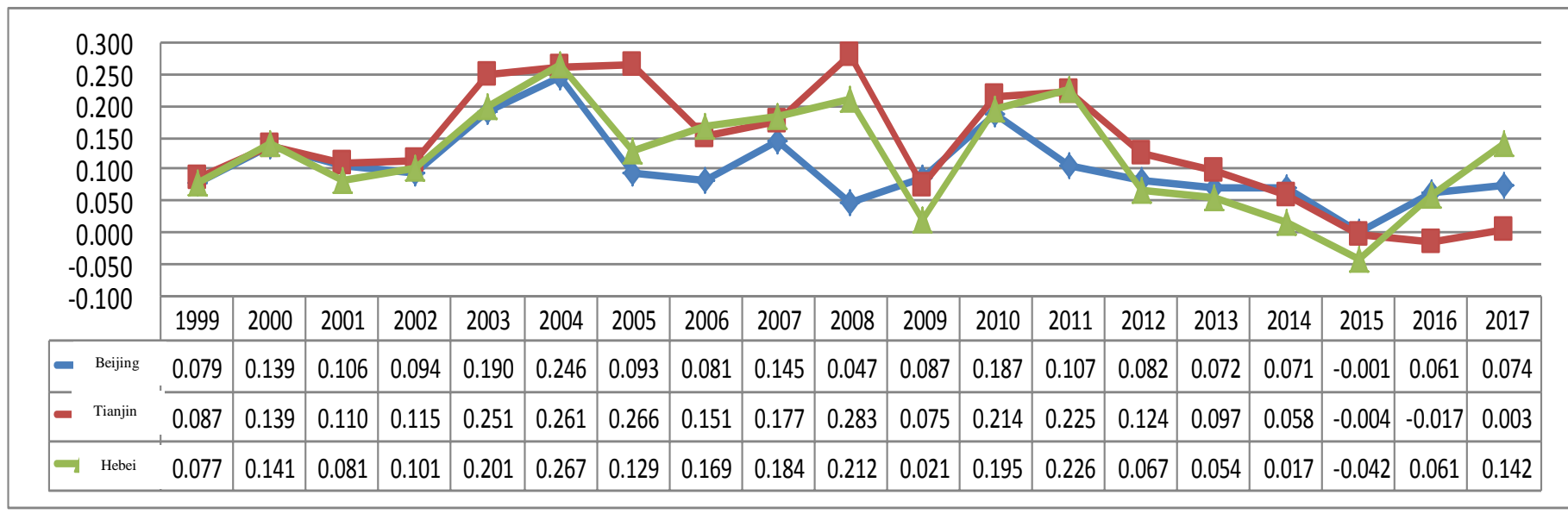

Fig. 1. Comparison of the economic growth rate of secondary industry in Beijing-Tianjin-Hebei region from 1999 to 2017.

From the perspective of the growth rate of total energy consumption in Beijing-Tianjin-Hebei region, Tianjin experienced a significant decline in 2003, but it has increased significantly in 2004 , and the overall growth rate is relatively stable. The growth rate of Hebei Province is relatively stable, but after 2005, the total energy consumption growth rate has shown a slowdown. The growth rate of total energy consumption in Beijing has been in a state of constant change, but the rangeability is small and the growth is relatively stable as shown in "Fig. 2".

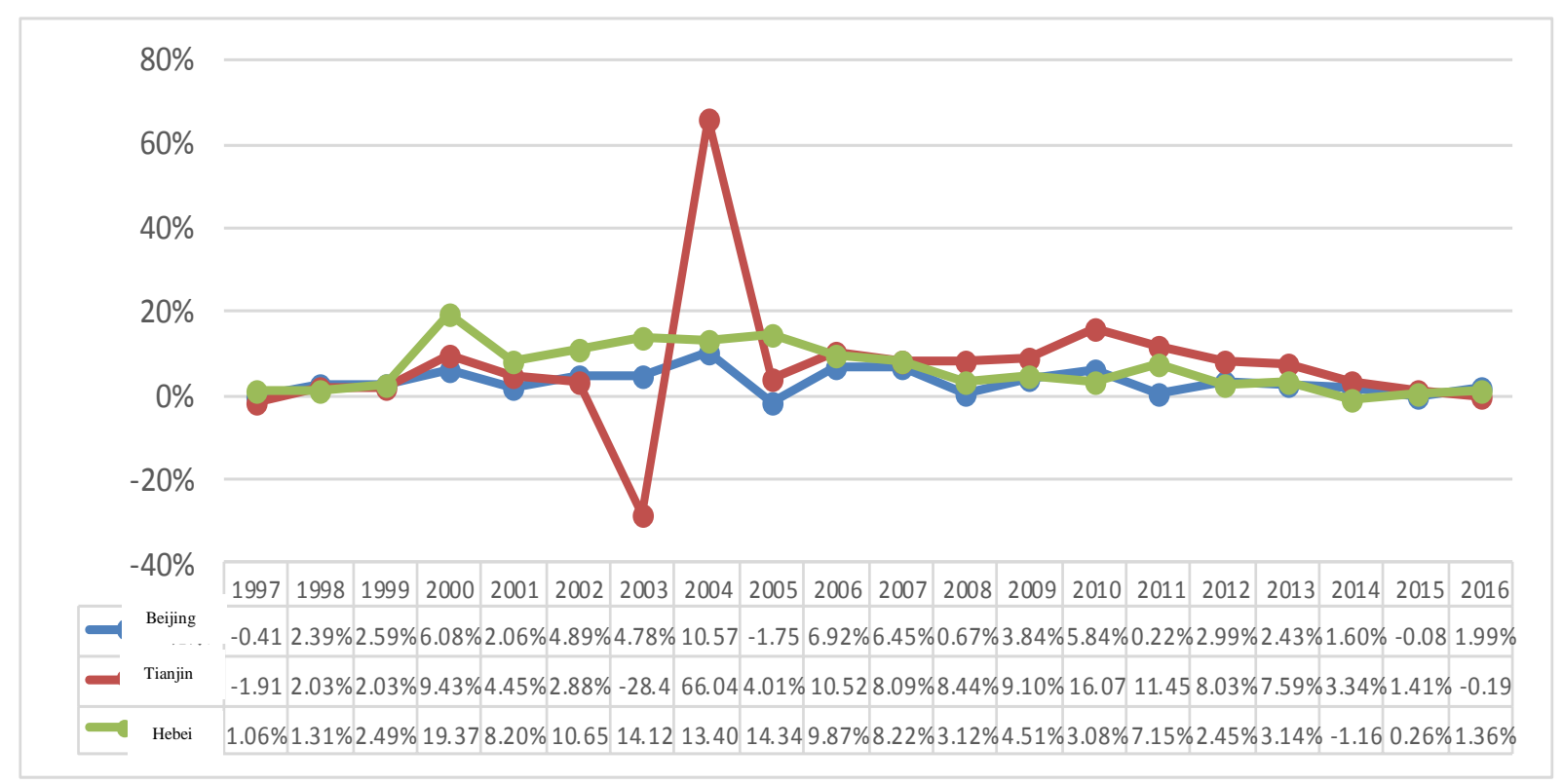

Fig. 2. Comparison of the growth rate of total energy consumption in Beijing-Tianjin-Hebei region 1997 to 2016.

\section{ANALYSIS OF THE DECOUPLING SitUATION OF} ECONOMIC DEVELOPMENT AND ENERGY CONSUMPTION IN BEIJING-TIANJIN-HEBEI REGION

The decoupling between economic development and energy consumption in Beijing-Tianjin-Hebei region mainly refers to the degree of dependence between economic growth and energy consumption in the process of economic development in Beijing-Tianjin-Hebei region, from strong correlation to weak correlation, and gradually weakening, and finally showing reverse or irrelevant situation. The specific performance is that with the economic growth of Beijing-Tianjin-Hebei region, the total energy consumption utilization achieves "zero growth" or "negative growth". The decoupling evaluation of economic development and energy consumption in Beijing-Tianjin-Hebei region determines whether the economic development and energy consumption of Beijing-Tianjin-Hebei region transforms from weak decoupling to strong decoupling based on the changes in economic development, total energy consumption and energy consumption efficiency indicators.

Referring to the index system of the OECD in the decoupling methodology, this paper introduces the changes in economic development, total energy consumption and energy consumption efficiency indicators, and comprehensively analyzes the decoupling situation of 
economic development and energy consumption in BeijingTianjin-Hebei region from 1997 to 2016. The analysis of decoupling situation of economic development and energy consumption in Beijing-Tianjin-Hebei region mainly reflects three aspects: first is economic driving indicators, such as GDP or different industrial output values; second is pressure status indicators, such as total energy consumption or different industrial energy sources consumption; third is energy consumption efficiency indicators, such as energy consumption per 10,000 yuan of GDP or energy consumption per unit of industrial output. Combined with the three indicators, it comprehensively reflects the decoupling situation relationship between economic development and energy consumption in Beijing-Tianjin-Hebei region as shown in "Table I".

TABle I. Decoupling Status of Economic Development And ENERgy Consumption in Beijing-Tianjin-Hebei Region

\begin{tabular}{|c|c|c|c|c|c|}
\hline Decoupling type & Economic driver & Stress state & Energy efficiency & $\begin{array}{c}\text { Decoupling elastic } \\
\text { coefficient }\end{array}$ & Decoupling discrimination \\
\hline \multirow{3}{*}{ Decoupling } & increase & decrease & enhancement & $\leq 0$ & strong Decoupling \\
\hline & increase & enlargement & enhancement & $(0,0.8)$ & weak decoupling \\
\hline & recession & decrease & enhancement & $\geq 1.2$ & Recessionary decoupling \\
\hline \multirow{3}{*}{ Negative decoupling } & recession & enlargement & reduce & $\leq 0$ & strong negative Decoupling \\
\hline & recession & decrease & reduce & $(0,0.8)$ & weak negative decoupling \\
\hline & increase & enlargement & improvement & $\geq 1.2$ & $\begin{array}{ll}\text { expansionary } & \text { negative } \\
\text { decoupling } & \\
\end{array}$ \\
\hline \multirow{2}{*}{ Link } & increase & enlargement & reduce & - & increase link \\
\hline & recession & decrease & reduce & - & recessionary link \\
\hline
\end{tabular}

a. Note: The decoupling elastic coefficient mainly refers to the ratio of the growth rate of the pressure state variable to the growth rate of the economic driving force variable, and aims to discriminate the decoupling situation of economic development and energy consumption utilization.

Using the data of Beijing Statistical Yearbook, Hebei Statistical Yearbook and Tianjin Statistical Yearbook over the years, with GDP representing economic driving force, energy consumption representing energy stress state, and GDP energy consumption index representing energy utilization efficiency, this paper illustrates the trajectory characteristics of economic growth and energy growth rate in Beijing-Tianjin-Hebei region by referring to "Table I", reflecting the decoupling situation of economic growth and energy consumption in different periods of economic and social development in Beijing-Tianjin-Hebei region in "Table II".

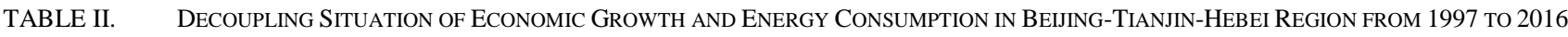

\begin{tabular}{|c|c|c|c|c|c|c|}
\hline Area & Years & $\begin{array}{l}\text { Annual GDP } \\
\text { growth rate }\end{array}$ & $\begin{array}{l}\text { Annual growth } \\
\text { rate of energy } \\
\text { consumption }\end{array}$ & $\begin{array}{l}\text { Ten thousand yuan } \\
\text { GDP energy } \\
\text { consumption index }\end{array}$ & $\begin{array}{l}\text { Decoupling } \\
\text { elastic } \\
\text { coefficient }\end{array}$ & $\begin{array}{c}\text { Decoupling } \\
\text { discrimination }\end{array}$ \\
\hline \multirow{5}{*}{ Beijing } & $1997-2000$ & $10.70 \%$ & $2.64 \%$ & 0.818 & 0.141 & weak decoupling \\
\hline & $2001-2005$ & $12.25 \%$ & $4.03 \%$ & 0.749 & 0.179 & weak decoupling \\
\hline & $2006-2010$ & $11.30 \%$ & $4.72 \%$ & 0.778 & 0.253 & weak decoupling \\
\hline & 2011-2015 & $7.62 \%$ & $1.42 \%$ & 0.802 & 0.114 & weak decoupling \\
\hline & 2016 & $6.80 \%$ & $1.99 \%$ & - & 0.239 & - \\
\hline \multirow{5}{*}{ Tianjin } & $1997-2000$ & $10.55 \%$ & $1.84 \%$ & 0.828 & 0.403 & weak decoupling \\
\hline & $2001-2005$ & $14.07 \%$ & $6.49 \%$ & 0.744 & 0.262 & weak decoupling \\
\hline & $2006-2010$ & $16.26 \%$ & $10.88 \%$ & 0.818 & 0.454 & weak decoupling \\
\hline & 2011-2015 & $12.49 \%$ & $6.65 \%$ & 0.798 & 0.471 & weak decoupling \\
\hline & 2016 & $9.10 \%$ & $-0.56 \%$ & - & -0.023 & - \\
\hline \multirow{5}{*}{ Hebei } & $1997-2000$ & $9.94 \%$ & $5.79 \%$ & 0.937 & 0.548 & weak decoupling \\
\hline & $2001-2005$ & $14.78 \%$ & $12.12 \%$ & 1.045 & 0.778 & increase link \\
\hline & $2006-2010$ & $15.32 \%$ & $5.72 \%$ & 0.784 & 0.309 & weak decoupling \\
\hline & 2011-2015 & $7.94 \%$ & $2.33 \%$ & 0.776 & 0.262 & weak decoupling \\
\hline & 2016 & $6.81 \%$ & $1.36 \%$ & - & 0.199 & - \\
\hline \multirow{5}{*}{$\begin{array}{l}\text { Beijing- } \\
\text { Tianjin- } \\
\text { Hebei region }\end{array}$} & $1997-2000$ & $11.78 \%$ & $4.56 \%$ & 0.876 & 0.348 & weak decoupling \\
\hline & $2001-2005$ & $16.24 \%$ & $9.54 \%$ & 0.787 & 0.514 & weak decoupling \\
\hline & $2006-2010$ & $15.95 \%$ & $6.21 \%$ & 0.679 & 0.321 & weak decoupling \\
\hline & 2011-2015 & $9.76 \%$ & $2.85 \%$ & 0.807 & 0.255 & weak decoupling \\
\hline & 2016 & $7.20 \%$ & $1.17 \%$ & $\longrightarrow$ & 0.162 & - \\
\hline
\end{tabular}

According to the respective economic development and energy consumption of Beijing-Tianjin-Hebei region, it can be seen that the economic development and energy consumption growth rate of Beijing-Tianjin-Hebei region generally rose first and then decreased, and then judging from the decoupling state, it can be seen that economic development and energy consumption in Beijing-TianjinHebei region have not yet been strongly decoupled. 


\section{ANALYSIS OF THE MECHANISM OF DECOUPLING BETWEEN ECONOMIC DEVELOPMENT AND ENERGY CONSUMPTION IN BEIJING-TIANJIN-HEBEI REGION}

Based on the analysis of the decoupling situation of economic development and energy consumption in BeijingTianjin-Hebei region, and the trend of growth in energy consumption of the three industries in Beijing-Tianjin-Hebei region, we can further explore and analyze the internal mechanism of decoupling between economic development and energy consumption in Beijing-Tianjin-Hebei region.

\section{A. Analysis of the Decoupling Mechanism of Beijing Economic Development and Energy Consumption}

From 1997 to 2016, Beijing's GDP growth rate showed a trend of "slow growth - slow decline - rapid decline - slow decline". The growth rate of energy consumption generally showed the situation of "rapid growth - slow growth - rapid decline - slow growth" in "Fig. 3", which increased from 37.192 million tons of standard coal in 1997 to 69.617 million tons of standard coal in 2016, but the energy consumption efficiency continued to increase.

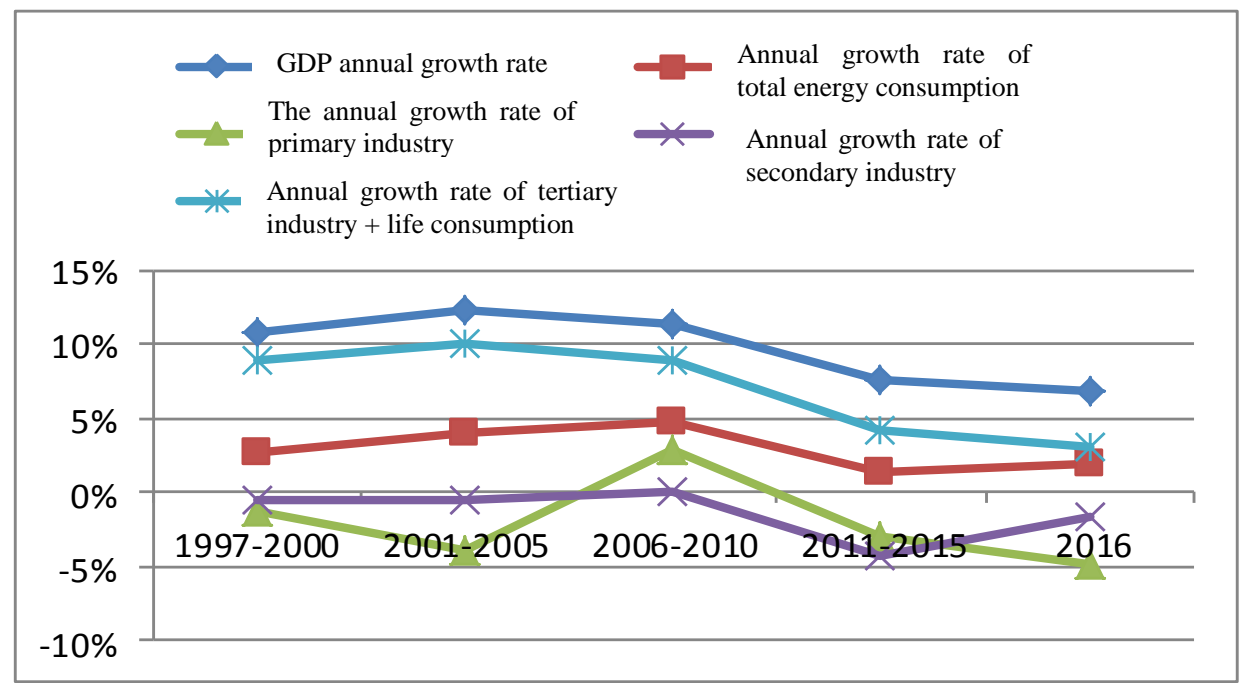

Fig. 3. Changes in GDP and energy consumption growth rates in Beijing from 1997 to 2016.

Since 1997, Beijing's energy consumption growth rate has generally been declining. The growth rate of total energy consumption is also affected by the growth of primary, secondary, and tertiary industry and consumer energy consumption. From the trend of the tertiary industry and the energy consumption of life consumption, the changes in the total energy consumption of the tertiary industry and energy consumption of life consumption are more prominent to the total energy consumption, because the total energy consumption and the growth rate change and the tertiary industry + the total energy consumption and growth rate of life consumption are more consistent as shown in "Fig. 3" and "Fig. 4". The precondition for the decoupling of Beijing economic development and energy consumption is to achieve zero growth in the tertiary industry and energy consumption of life consumption.

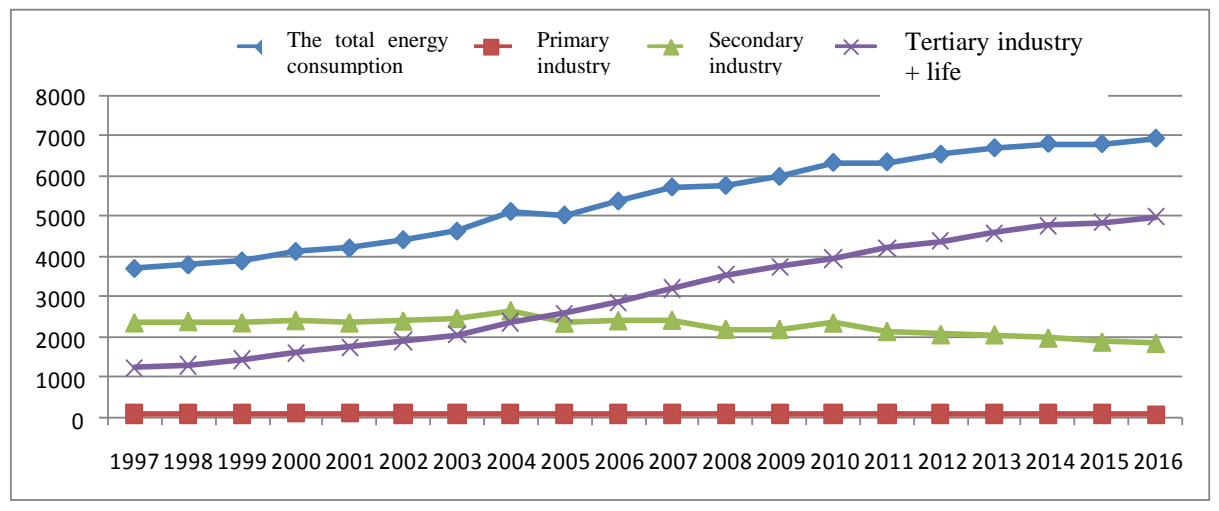

Fig. 4. Changes in energy consumption of the three industries in Beijing from 1997 to 2016.

Because Beijing was in the post-industrial era, the tertiary industry accounted for a relatively large proportion. Since 1997, the proportion of primary industry, secondary industry, tertiary industry and consumer energy consumption in Beijing has been constantly changing. The proportion of primary industry in total energy consumption has remained basically unchanged, and the proportion of secondary industry has been declining. The proportion of the tertiary industry + living consumption is rising. It can be seen that the incremental change of the tertiary industry + life 
consumption in the total energy consumption is more

prominent as shown in "Fig. 5".

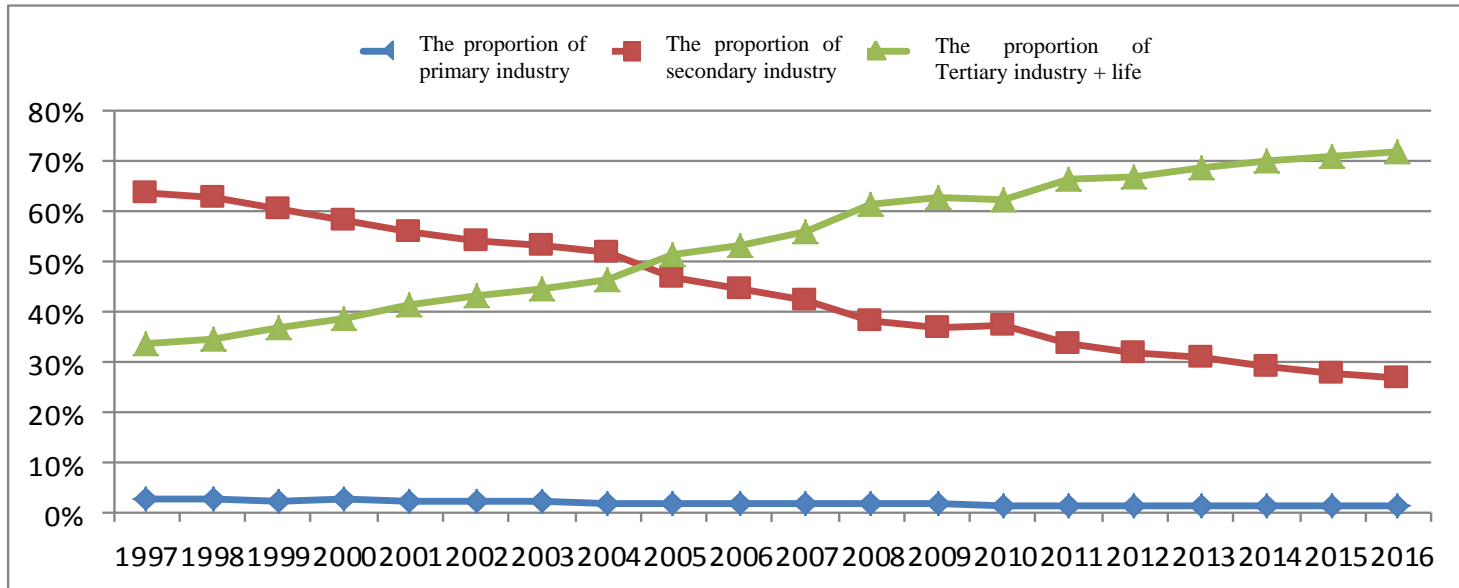

Fig. 5. Changes in the proportion of energy consumption of three industries in Beijing from 1997 to 2016.

From "Fig. 3", it can be found that Beijing's GDP growth rate and the total energy consumption growth rate are basically the same, which further indicates that Beijing's economic development depends on energy consumption, and the two have not yet been decoupled. "Fig. 4" and "Fig. 5" indicates the precondition for decoupling is to achieve zero growth in the tertiary industry + energy consumption of life consumption.

\section{B. Analysis of the Decoupling Mechanism of Economic Development and Energy Consumption in Tianjin}

From 1997 to 2016, Tianjin's GDP growth rate showed a trend of "rapid growth - slow growth - rapid decline - slow decline", and the growth rate of energy consumption showed a trend of "slow growth - rapid growth - slow decline rapid decline" as in "Fig. 6" from 23.137 million tons of standard coal in 1997 to $80,414,300$ tons of standard coal in 2016, but the energy consumption efficiency is increasing.

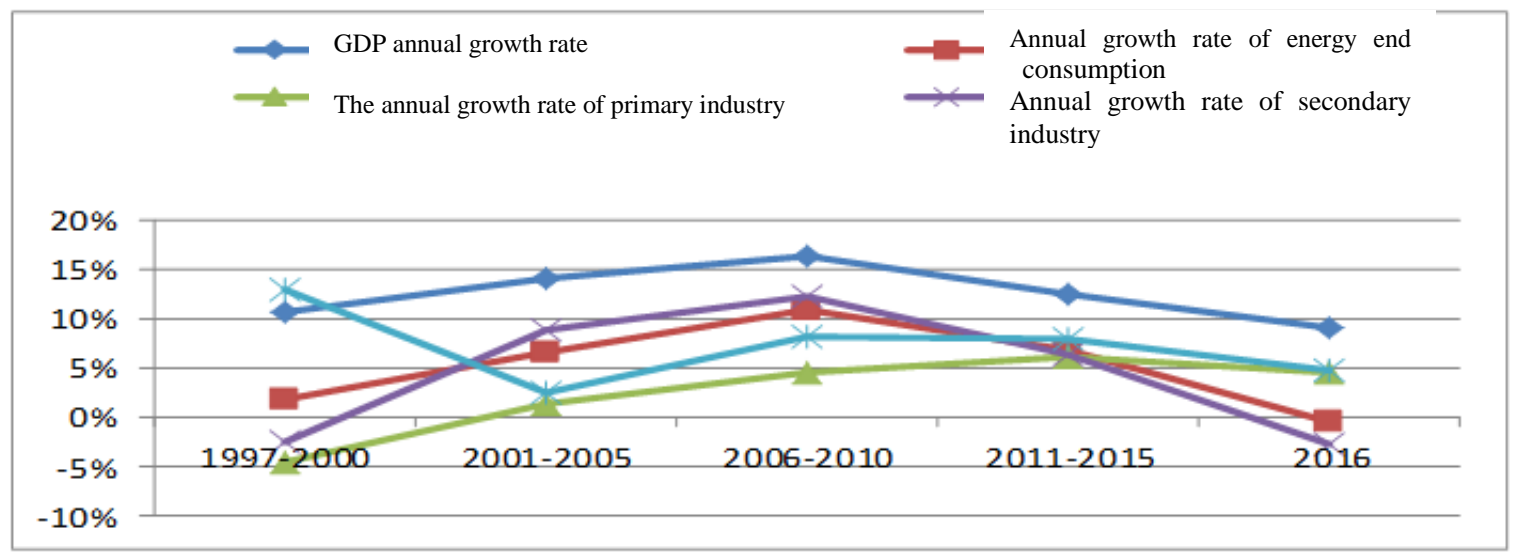

Fig. 6. Changes in GDP and energy consumption growth rates of Tianjin from 1997 to 2016.

Since 1997, the growth rate of energy consumption in Tianjin generally rose first and then declined. The growth rate of total energy consumption is also affected by the growth of primary, secondary, and tertiary industry and consumer energy consumption. From the trend of energy consumption in the secondary industry, the incremental change in energy consumption of the secondary industry in Tianjin is more pronounced, and the change in total energy consumption and growth rate is more consistent with the curve of the total energy consumption and growth rate of the secondary industry, as shown in "Fig. 6" and "Fig. 7". Thus, the precondition for the decoupling of economic development and energy consumption in Tianjin is to achieve zero growth in energy consumption in the secondary industry. 


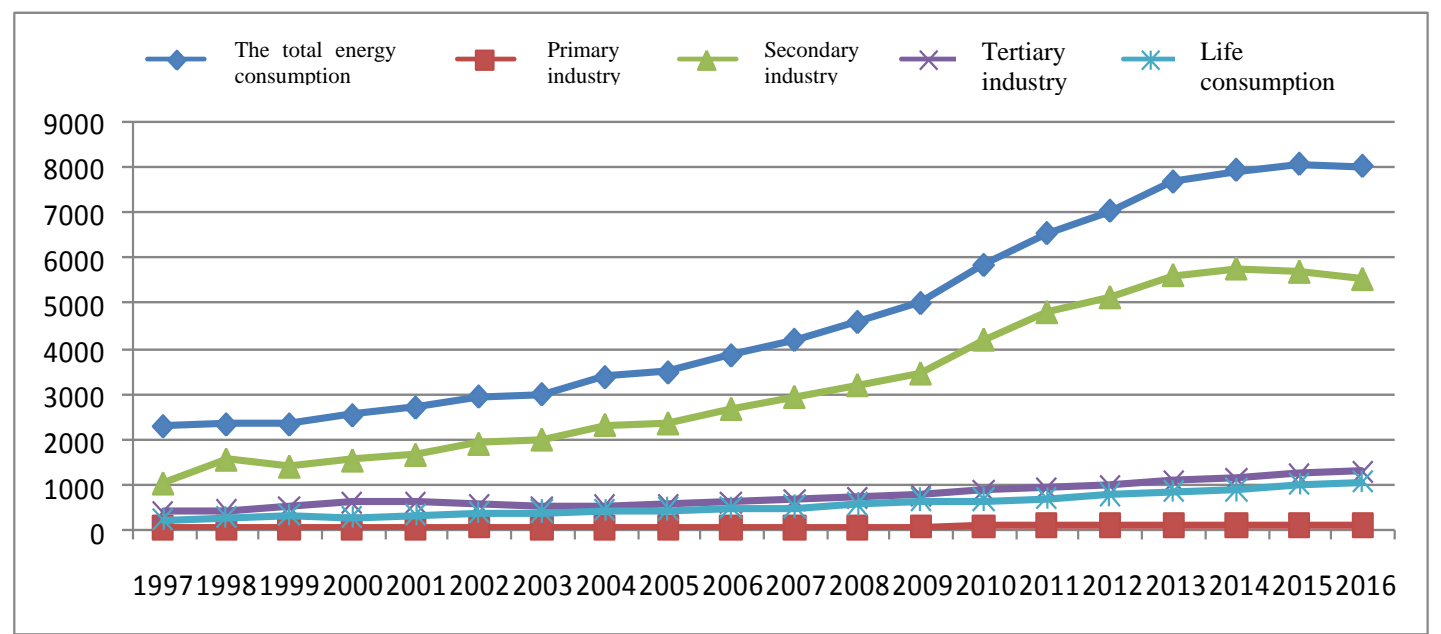

Fig. 7. Changes in energy consumption of three industries in Tianjin from 1997 to 2016.

Because Tianjin is in the post-industrial era, the secondary industry accounts for a relatively large proportion. Since 1997, the proportion of primary industry, secondary industry, tertiary industry and consumption energy consumption in Tianjin has also been changing. The proportion of energy consumption in the primary industry has remained basically unchanged, and the proportion of energy consumption in the secondary industry rose with fluctuation. The proportion of tertiary industry + energy consumption of life consumption is declining with fluctuation, and the high proportion of the secondary industry has highlighted the incremental change in total energy consumption as shown in "Fig. 8".

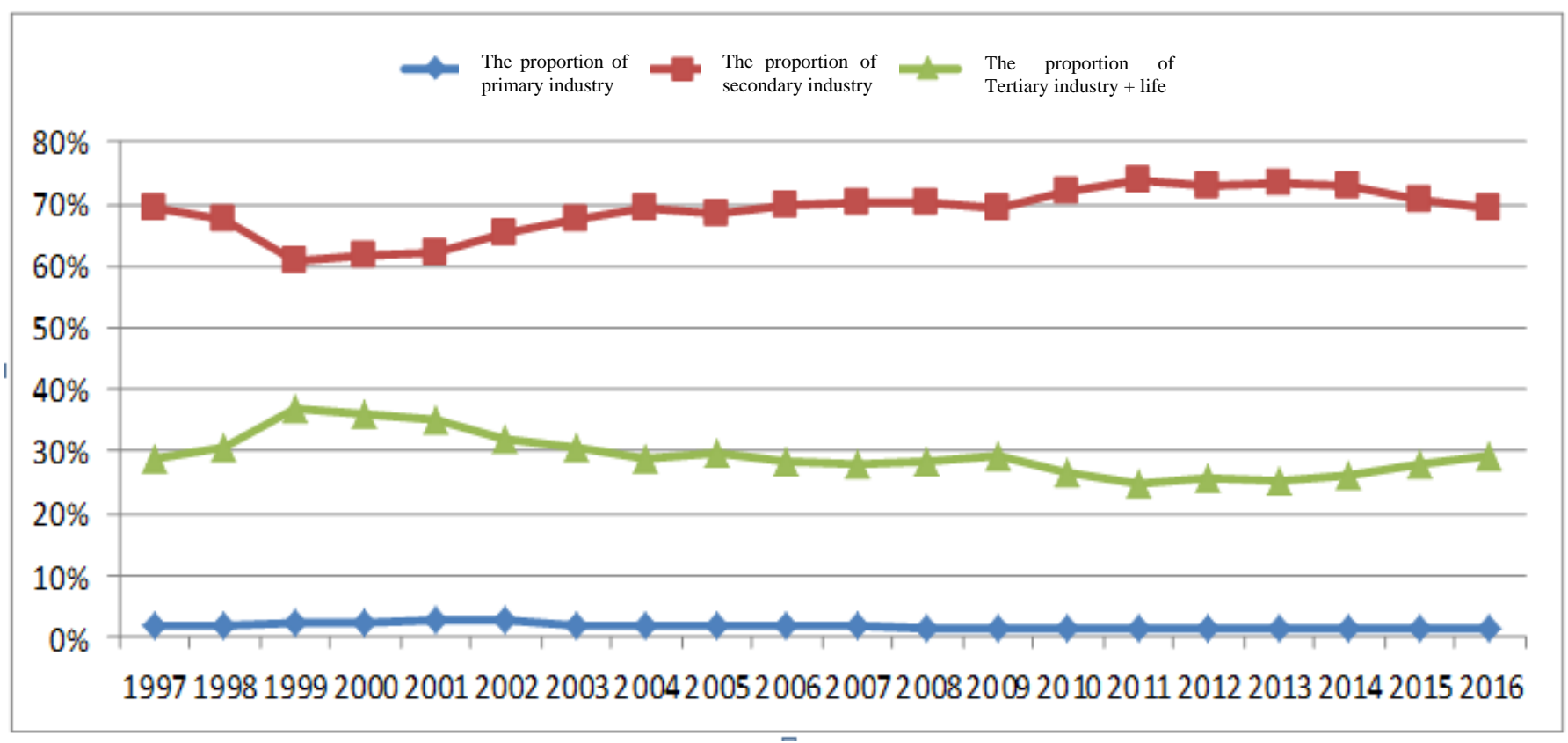

Fig. 8. Changes in the proportion of energy consumption of three industries in Tianjin from 1997 to 2016.

From "Fig. 8", Tianjin's GDP growth rate and the total energy consumption growth rate are basically the same, which further indicates that Tianjin's economic development depends on energy consumption, and the two have not yet been decoupled. From "Fig. 7" and "Fig. 8", the precondition for decoupling is to achieve zero growth in energy consumption of the secondary industry.
C. Analysis of the Decoupling Mechanism of Economic Development and Energy Consumption in Hebei Province

From 1997 to 2016, Hebei's GDP growth rate showed a trend of "rapid growth - slow growth - rapid decline - slow decline". The growth rate of energy consumption generally showed a trend of "rapid growth - rapid decline - rapid 
decline - slow decline" as shown in "Fig. 9", from the 90.31 million tons of standard coal in 1997 to 297,744 tons of standard coal in 2016, but the overall energy consumption efficiency is increasing.

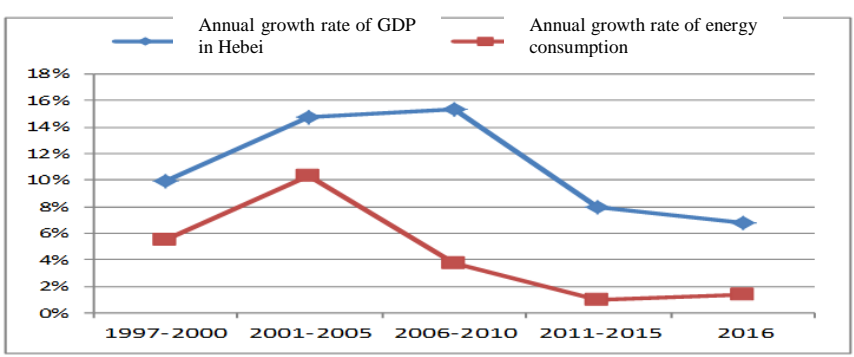

Fig. 9. Changes in GDP and energy consumption growth rate in Hebei from 1997 to 2016
Since 1997, the growth rate of energy consumption in Hebei generally rose firstly and then declined. From the perspective of the trend of energy consumption in Hebei's secondary industry after 2005 , the incremental change in energy consumption in Hebei's secondary industry is more pronounced. The change in total energy consumption and growth rate in Hebei after 2005 is more consistent with the total energy consumption and growth rate of the secondary industry as shown in "Fig. 9" and "Fig. 10". The precondition for the decoupling of economic development and energy consumption in Hebei is to achieve zero growth in energy consumption in the secondary industry.

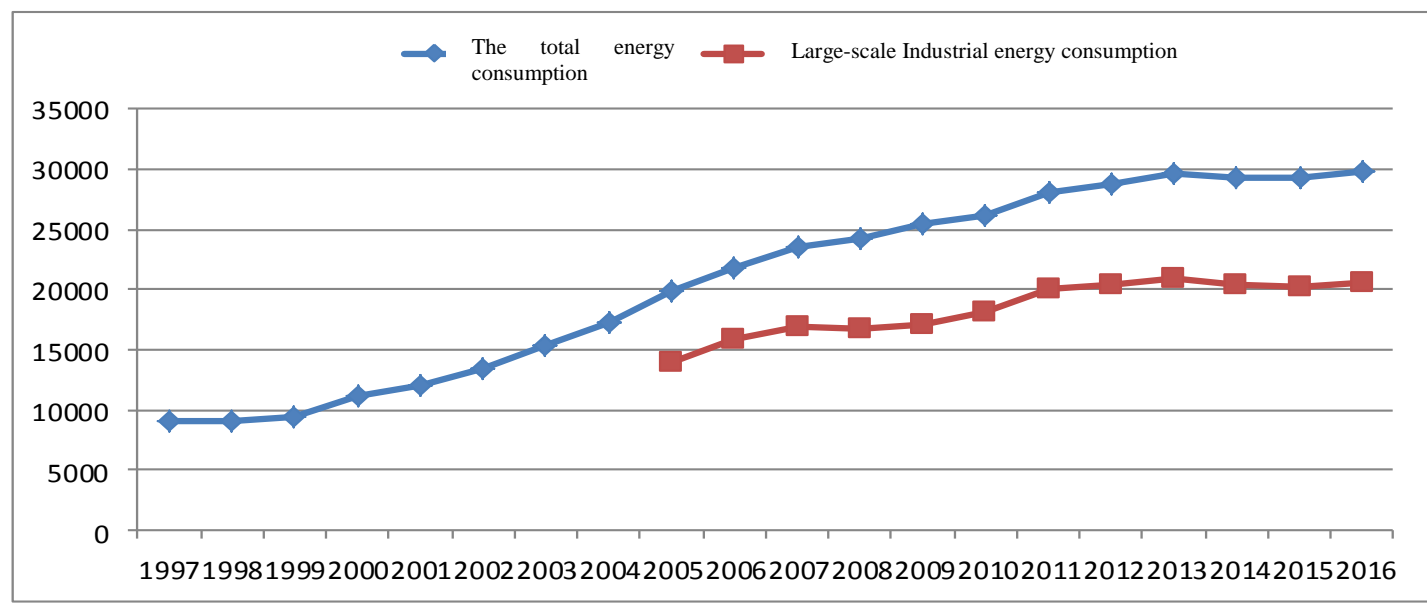

Fig. 10. Changes in energy consumption in Hebei from 1997 to 2016

Since Hebei is at the middle phase of industrialization, the secondary industry accounts for a considerable proportion. Since 2005, the energy consumption ratio of the secondary industry in Hebei has fluctuated at $70 \%$, and the non-secondary industry has fluctuated at $30 \%$. The high proportion of the secondary industry has significantly increased the incremental change in total energy consumption as shown in "Fig. 11".

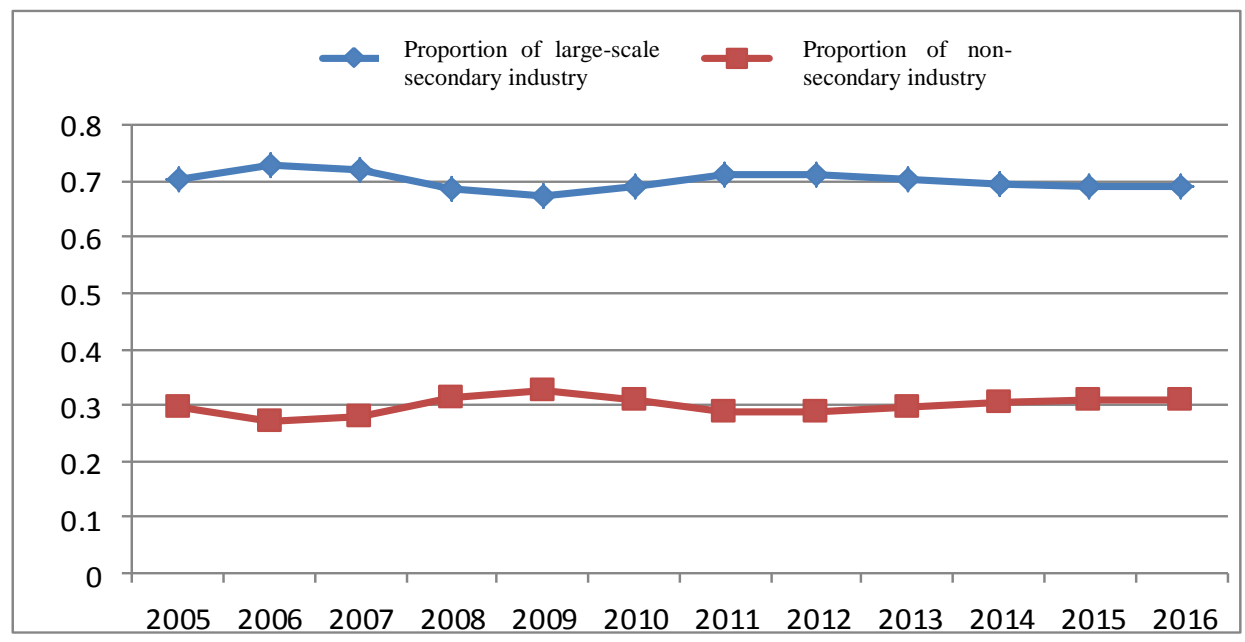

Fig. 11. Changes in the proportion of energy consumption in Hebei from 2005 to 2016

From "Fig. 9", Hebei's GDP growth rate and energy consumption growth rate after 2005 are basically the same, which further indicates that Hebei's economic development depends on energy consumption, and the two have not yet been decoupled. "Fig. 10" and "Fig. 11" state that the 
prerequisite for achieving decoupling is to achieve zero growth in the secondary industry.

Overall, the Beijing-Tianjin-Hebei energy consumption curve is consistent with the trend of Hebei energy consumption in "Fig. 12". The precondition for the decoupling of Beijing-Tianjin-Hebei economic development and energy consumption is to achieve zero growth in Hebei's energy consumption.

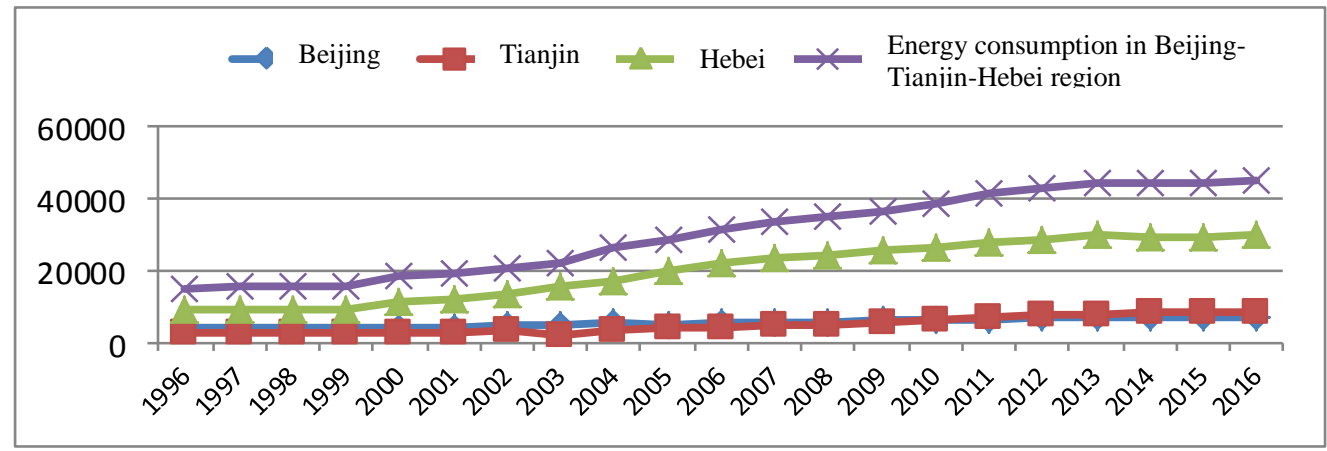

Fig. 12. Changes in energy consumption of Beijing-Tianjin-Hebei region.

\section{CONCLUSION}

Based on the relevant literature research and data collection, the economic development and energy consumption decoupling situation in Beijing, Tianjin and Hebei were analyzed. On this basis, the paper analyzes the incremental and proportional changes of economic growth and utilization of energy consumption of three industries in Beijing, Tianjin and Hebei in different periods since 1997, and systematically analyzes the internal mechanism of realizing the decoupling between economic development and energy consumption. The results show that decoupling of economic development and energy consumption has not yet been achieved in Beijing, Tianjin and Hebei at the present stage. The key to the decoupling of economic development and energy consumption in Beijing lies in the decoupling of tertiary industry + energy consumption of life consumption and economic development. The key to Tianjin and Hebei lies in realizing the decoupling of energy consumption in the secondary industry and economic development, and the key to the decoupling of economic development and energy consumption by Beijing-Tianjin-Hebei is to realize the decoupling between Hebei's energy consumption and economic development. The transformation and upgrading of the industrial structure of Beijing-Tianjin-Hebei has promoted the reduction of energy consumption, but there are still differences in Beijing-Tianjin-Hebei region. Therefore, it is imperative to strengthen the coordinated development of Beijing, Tianji and Hebei. All relevant departments should adjust and optimize the industrial structure according to the respective positioning of Beijing, Tianjin and Hebei, vigorously eliminate high-energy-consuming industries, and increase technological innovation, thereby reducing energy consumption and improving energy efficiency, and ultimately reducing economic development for energy consumption.

\section{REFERENCES}

[1] OECD. Indicators to measure decoupling of environmental pressure from economic growth [R]. Paris: OECD, 2002.

[2] Ayres R U, Ayres L W, Warr B. Energy, power and work in the US economy, 1900-1998 [J]. Energy, 2003, 28(3): 219-273.

[3] OECD. Effects of quantities constrains on the degree of decoupling of crop support measures [R]. Paris: OECD, 2005.

[4] Vehmas J, Kaivo-oja J, Luukkanen J. Comparative de-link and re-link analysis of material flows in EU-15 membercountries [R]. Wuppertal: Con Account Conference, 2003

[5] Tapio Petri. Towards a theory of decoupling: Degrees of decoupling in the EU and the ease of road traffic in Finland between 1970 and 2001 [J]. Journal of Transport Policy, 2005(12): 137-151.

[6] De Bruyn S M, Opschoor J B. Developments in the throughput-income relationship: Theoretical and empirical observations[J]. Ecological Economics, 1997, 20(3): 255-268.

[7] Vehmas J, Kaivo-oja J, Luukkanen J. Global trends of linking environmental stress and economic growth [R]. Turku:Finland Futures Research Centre, 2003: 6-9.

[8] Climent F, Pardo A. Decoupling factors on the energy-output linkage: The Spanish case [J]. Energy Policy, 2007, 35 (1): 522-528.

[9] Tapio P. Towards a theory of decoupling: Degrees of decoupling in the EU and the case of road traffic in finland between 1970 and 2001 [J]. Transport Policy, 2005, 12(2): 137-151.

[10] Sigrid S. Delinking economic growth from environmental degradation: A literature survey on the environmental Kuznets Curve Hypothesis [J]. Wirtschafts Universitat Wien Working Paper, 1999(6): 1-24.

[11] Zhong Taiyang, Huang Xianjin, Han Li, et al. Progress in analysis and research of decoupling of resources and environment[J]. Journal of Natural Resources, 2010, 25(8): 1400-1412.

[12] Chen Huan, Zhu Qingyuan, Xin Lu. Research on the Relationship between Economic Growth and Energy Carbon Emission in BeijingTianjin-Hebei Region - Based on the Analysis of the Application of Decoupling Theory[J]. Price:Theory \& Practice, 2016(12): 180-183.

[13] Lv Qian, Gao Junlian. Analysis of transportation carbon emission model and driving factors in Beijing-Tianjin-Hebei region [J]. Ecological Economy, 2018, 34(01): 31-36.

[14] Cheng Haisen, Ma Jing, Fan Xinye. Research on the relationship between energy consumption, economic growth and carbon emissions in Beijing-Tianjin-Hebei region [J]. Modern Management Science, 2017(11): 81-83.

[15] Wang Zhongyu. Empirical Study on the Relationship between Energy Consumption, Carbon Emission and Economic Growth in Beijing- 
Tianjin-Hebei Region[J]. Journal of Industrial Technological Economy, 2017, 36(01): 82-92.

[16] Zhou Guofu, Gong Lili. Analysis of carbon footprint of energy consumption in Beijing-Tianjin-Hebei region and its influencing factors [J]. On Economic Problems, 2014(08): 27-31.

[17] He Yin, Cai Mantang. The Decoupling Relationship between Economic Growth and Resource Environment in Beijing-TianjinHebei Region[J]. Journal of Beijing Institute of Technology(Social Sciences Edition), 2016, 18(05): 33-41. 